\title{
Research on Discrete Dynamic Forecasting Model of Government Human Resources
}

\author{
Qin $\mathrm{Li}^{1}$ \\ ${ }^{1}$ Henan Institute of Science and Technology, Xinxiang City, Henan Province, China 453003
}

\begin{abstract}
For the evolution of complex system, especially the unbalanced complex system, dynamic is its universal attribute. In this paper, by introducing the discrete dynamic system model in complex system research, a method of establishing the discrete dynamic system model of government human resources system is proposed from the vertical level. In this study, human resources were forecasted by the method of manpower/population ratio, linear regression and grey system, and the total number of health human resources in A city from 2018 to 2022 was forecasted by weighted average combination method. The results show that we should make great efforts to innovate the training mode of health personnel, improve the enthusiasm of staff, and reasonably control the expansion of hospitals.
\end{abstract}

\section{Introduction}

The term "human resource" was first put forward by the famous American management scientist named Peter F. Drucker. It refers to the potential usefulness of people in a certain social area, which can be used as a factor of production in economic activities, and can promote and promote the whole social and economic development of special resources. Today's world is a rapidly changing world, and today's era is a challenging era. With the rapid development of economy and the rapid development of science and technology, the management of the public sector has undergone profound changes. It is no longer the original management, but is gradually replaced by a new, more scientific and suitable management model to meet the needs of the times. Faced with such great changes, the society has put forward higher and newer requirements for public human resources management. How to have many high-quality talents to make public management more effective is the problem that human resources forecasting should solve.

Effective human resource forecasting can make the organization adapt to the environment effectively and cope with various changes. At the same time, human resource prediction can optimize the use of talents, tap personal potential, help personnel improve their quality and personal ability, make them get job development opportunities, meet the development requirements of talents, reduce staff dissatisfaction, and avoid unused and disorderly flow of talents. On the other hand, modern human resources management, especially government human resources management, is gradually developing into strategic human resources management, becoming an important part of the national management system, and embodied in its overall strategic relationship with the organization. Therefore, human resources forecasting and planning has become a link to achieve the overall planning of government departments and human resources management of the department, which is not only beneficial to the realization of the overall strategy of the organization, but also beneficial to the micro-management of the organization.

The modelling methods of discrete dynamic systems mainly include state space model, system dynamics model and various automaton network models. The state space model is a mathematical model describing the dynamic behaviour of the system by taking the state of the system as a variable. It is suitable for the modelling of dynamic systems with time-delay characteristics. The discrete cellular automata model in discrete time is a typical representative of the network automata model. It has been widely applied in the research of complex systems.

\section{Main methods of human resources forecasting}

\subsection{Manpower and population ratio}

The ratio of manpower to population method does not involve the utilization of health services, needs and other indicators can only be roughly estimated. Therefore, it is more suitable for the macro prediction of the development trend of health human resources. It is difficult to understand the internal structure of grassroots health human resources and the role of improving the quantity of health services and work efficiency in human resources planning. If the inappropriate ratio of human population is chosen as the prediction criterion, it may result in waste of resources and have a negative 
impact on human policy. However, the method of ratio of manpower to population is simple and feasible. Under the condition of stable economic level, policy environment and other factors, this method is timesaving and labour-saving, and has relatively strong use value. This method needs less information and costs less. It only considers population factors, but does not involve the social economy, technology and health level of the population. Specifically, the method first predicts the ratio of various health resources to population in the target year, then multiplies the ratio from the predicted population in the target year to obtain the demand for health resources in the target year. It is pointed out that this method should be applied to distinguish the resource requirements of the floating population from those of the permanent population. This method is simple and easy to understand. It has been used in many countries and regions to forecast the human demand for health. It belongs to expansive prediction. However, this method does not consider the internal structure of human health, service efficiency and the actual needs of residents and other factors, which may lead to excessive prediction standards and waste of resources.

\subsection{Linear regression method}

The changes of social and economic phenomena are often influenced by many factors. Therefore, multivariate regression analysis is generally needed. We call regression with two or more independent variables multivariate linear regression. There are many factors affecting the allocation of health resources, including economic, social and cultural aspects. Multivariate linear regression can consider many factors, use historical data to establish regression prediction model, estimate parameters and input values, and combine local economic and social conditions to estimate the number of human and equipment needs. We use linear regression method to study the relationship between the marker value and the supply of medical doctors, find out the linear regression relationship between the marker value and medical doctors, establish the linear regression equation, and use the equation to estimate the allocation standard of doctors in different regions according to the marker value. This method is mathematically rigorous, but in practical application, we should carefully analyse the relationship between dependent variables and independent variables. We should not treat statistical quantitative relations as causality. We should be cautious in selecting independent variables. In addition, there are certain preconditions for the application of these methods. The past resources must have reached a high utilization rate, otherwise the resource allocation scheme calculated according to this will continue to retain the shortcomings of the past and current resources allocation. When the dimension of independent variable increases from one dimension, the linear model we fit can also be extended to a plane. In binary linear regression model, it can be regarded as sample regression plane, when we use samples as training set. The plane we fit is the linear regression plane. When we use all the data, we get the global regression plane.

Assuming that a dependent variable $\mathrm{y}$ is affected by $\mathrm{k}$ independent variables $x_{1}, x_{2}, \ldots, x_{k}$. The N-group observation values are $\left(y_{a}, x_{1 a}, x_{2 a}, \ldots, x_{k a}\right)$ and $a=$ $1,2, \ldots, n$. Then, the structural form of the multivariate linear regression model is:

$$
y_{a}=\beta_{0}+\beta_{1} x_{1 a}+\beta_{2} x_{2 a}+\ldots+\beta_{k} x_{k a}+\varepsilon a
$$

Among the formula, $\beta_{0}, \beta_{1}, \ldots, \beta_{k}$ are undetermined parameters; $\varepsilon_{a}$ is random variable. If $b_{0}, b_{1}, \ldots, b_{k}$ are respectively the fitting values of $\beta_{0}, \beta_{1}, \beta_{2} \ldots, \beta_{k}$. The regression equation is:

$$
\hat{\mathrm{y}}=b_{0}+b_{1} x_{1}+b_{2} x_{2}+\ldots+b_{k} x_{k}
$$

Among the above formula, $b_{0}$ is a constant; $b_{1}, b_{2}, \ldots, b_{k}$ are partial regression coefficients. In multivariate linear regression analysis, the sum of regression squares represents the total effect of all $\mathrm{k}$ independent variables on the variation of $y$. It can be calculated by following formula:

$$
U=\sum_{a=1}^{n}\left(\hat{y}_{a}-\bar{y}\right)=\sum_{i=1}^{k} b_{i} L_{i y}
$$

The residual sum of squares is $Q=\sum_{a=1}^{n}\left(y_{a}-\right.$ $\left.\hat{y}_{a}\right)^{2}=L_{y y}-U$

They also represent similar meanings, that is, the larger the sum of regression squares, the smaller the sum of residual squares $\mathrm{Q}$, and the better the regression model is. F statistic is:

$$
F=\frac{U / k}{Q /(n-k-1)}
$$

After calculating the statistic F, we can check the F distribution table to test the significance of the model.

\subsection{Grey model}

The system with definite part information and unclear part information is called grey system. Grey transverse model, which was put forward by Professor Deng Julong in $1980 \mathrm{~s}$, refers to the differential equation dynamic model established by discrete data series in grey system theory, referred to as GM model. This method discovers and grasps the development law of the system by processing the original data and establishing the grey model, and makes a scientific prediction of the future state of the system. The characteristic of grey system theory research is that it overcomes the weakness of probability statistics, finds rules from cluttered, limited and discrete data, establishes models, and then makes corresponding analysis and prediction. At the same time, the grey parameters can be corrected in time so that the predicted values can be generated dynamically, so that a relatively long-term prediction can be made by using a shorter sequence, which is representative. However, the model does not fully consider the effects of population health needs, policy impact, budget pressure, social factors and changes in the five-life system. Grey forecasting method can effectively predict government human resources for uncertain systems with fewer data samples. Grey forecasting method does not require better distribution of sample data, and has strong adaptability when the original data of government human resources mutates. After the above processing, the data is basically suitable for modelling. The traditional prediction model 
is $\operatorname{GM}(1,1)$ model, whose original form is shown as follows: $x^{(0)}(k)+a x^{(1)}(k)=b$. The basic form is: $x^{(0)}(k)+a z^{(1)}(k)=b$.

The equation is to use the $z^{(1)}(k)$ to replace $x^{(1)}(k)$ to make the data smoother. The data $z^{(1)}(k)=$ $\frac{1}{2}\left(x^{(1)}(k-1)+x^{(1)}(k)\right)$ is called equation background value. $-\mathrm{a}$ is development coefficient and $\mathrm{b}$ is the grey action. Here $\mathrm{a}$ and $\mathrm{b}$ are obtained by least square method.

The albino equation is: $\frac{d x^{(1)}}{d t}+a x^{(1)}(k)=b$.

The time response function is $x^{(1)}(t)=$ $\left(x^{(1)}(1)-\frac{b}{a}\right) e^{-a(t-1)}+\frac{b}{a}$.

The time response sequence is $\hat{x}^{(1)}(k+1)=$ $\left(x^{(0)}(1)-\frac{b}{a}\right) e^{-a k}+\frac{b}{a}$.

The reduction value is $\hat{x}^{(0)}(k)=\hat{x}^{(1)}(k+1)-$ $\hat{x}^{(1)}(k)=\left(1-e^{a}\right)\left(x^{(0)}(1)-\frac{b}{a}\right) e^{-a k}$.

In order to solve the model, the least squares method is used to get the solution of $a$ and $b$, and then the whitening differential equation is used to get the solution.

\subsection{Combination forecasting}

Combination forecasting algorithm is a combination of two or more different single forecasting algorithms for the same sinter quality parameter forecasting problem. The research shows that the combined forecasting algorithm can make full use of the information provided by various single forecasting methods, and does not need to find the optimal single forecasting model. The combined forecasting model is superior to the single forecasting model in forecasting accuracy. The ratio of manpower to population method is a simple prediction of the discrete dynamics of government human resources. Grey forecasting method focuses on the white part of the non-linear mapping of government human resources forecasting model, while the multi-linear regression method highlights the black part of the non-linear mapping of government human resources forecasting model. They are not mutually exclusive. Combining the three single prediction models with the combination algorithm can make the single prediction results complement each other to reduce the sensitivity of the prediction results to a single poor prediction method and improve the accuracy and reliability of the prediction. The optimal combination forecasting is to construct the objective function according to some optimal criterion, and solve the maximum or minimum of the objective function under the constraints to obtain the weighting coefficients of the combined forecasting model, which are the optimal weighting coefficients of each single forecasting model. The least square method is used to determine the weight coefficients.

$$
\mathrm{k}=\frac{E^{-1} R}{R^{T} E^{-1} R}
$$

And $R^{T} K=1$. Among them, $K=$ $\left(k_{1}, k_{2}, \ldots, k_{m}\right), \sum_{i=1}^{m} k_{i}=1, k_{i} \geq 0, i=1,2, \ldots, m$.
$\mathrm{E}=\left(e_{1 t}, e_{2 t}, \ldots, e_{m t}\right)$ and $e_{i t}$ is to express the prediction error of the ith prediction method in the $t$ year.

\section{Concept and features of government health human resources}

\subsection{Concept}

Human resources in government departments refer to the total labour capacity of all kinds of personnel working in government departments. Human resources of government departments are a part of human resources of the whole society. The basis of human resource forecasting in government departments is organizational development planning and annual budget. The forecast of human resources should be based on a dynamic point of view, taking into full account the changing factors such as the increase of labour productivity, the improvement of working methods, the improvement of mechanization and automation level during the forecast period. Therefore, the prediction of human resources in government departments should include not only the prediction of the number of human resources in government departments, but also the prediction of the quality structure and ability structure of personnel in government departments. There are two concepts of health human resources: broad sense and narrow sense. It refers to all kinds of professional health personnel engaged in medical treatment and nursing, rural nonproductive health personnel, preparatory health personnel and potential health personnel; narrowly, it mainly refers to professional health personnel. In this paper, the concept of "potential health workers" in the former concept is narrow because of its large scope and disadvantage for analysis. Professional health personnel generally refer to people who have received different education and vocational training to provide health services and contribute their talents and wisdom according to people's health needs. It can reflect not only the level of health services in a country, but also the health level of people to a certain extent. However, the training of health manpower is a long process. How to meet the needs of social development for health manpower, it is necessary to formulate scientific, rational and effective health manpower planning and policies. Health manpower planning refers to the process of estimating the number and type of health personnel needed to achieve the intended health goals, improve people's health level. Prediction of health human resources is one of the important contents of health human resources planning. Accurate prediction of the number of health technicians is the premise and basis for optimizing the allocation of resources and formulating health resource planning scientifically to ensure the realization of health strategic objectives and tasks.

\subsection{Features}

Health human resources are characterized by long training cycle, duality, timeliness, regeneration, continuity and knowledge and technology intensiveness. There are differences in professional and technical 
knowledge and service content in health human resources. At present, the scale of health worker's labour is becoming larger and larger, and the social connection of health care service activities is becoming more and more extensive. It needs various professionals such as prevention, treatment, rehabilitation, nursing, health technology, education, scientific research, pharmacy, laboratory and so on. More importantly, the division of labour between prevention, medical care, medical technology, medical professions and logistics departments should be clearly defined, closely cooperated, and the overall cooperation should be brought into play. Function. Therefore, in order to achieve the best results, how health personnel with different educational background, different specialties and different functions should be matched in health human resources, how to optimize the combination of different levels of health personnel at different levels, which are much more complex than other resources allocation and combination. The development of health human resources takes a long time and has many restrictions. It usually takes five years to train a medical undergraduate. In foreign countries, medical undergraduates must be engaged in clinical work for five to seven years after graduation before they can apply for a doctor's license. The combination of health human resources is a complex and changing health human resources in the continuous re-education and knowledge updating. The key to the service provided by health institutions to the society is the organizational knowledge system consisting of the knowledge and experience of employees. The development of organizational knowledge system depends on the accumulation of personal knowledge and experience as well as the diffusion and transfer within the organization. Therefore, the key to the core competitiveness of health institutions is the integration of employee knowledge and employee knowledge. The quality of service in health institutions is related to staff's knowledge, experience and skills, but the influence of employee's professional ethics and work attitude on service quality is also very important.

\section{Current situation analysis of health human resources of $A$ city}

According to the Statistical Yearbook of Health and Family Planning of A City in 2018, there were 438,000 health workers in A city by the end of 2017 , of whom 33,600 were health technicians, accounting for $76.59 \%$ of the total number of health human resources. Health technicians of every 1,000 population were mainly used to reflect the allocation of health human resources in different periods and regions, and the results were comparable. Comparing with each other The changing trend of birth technicians per 1,000 population in A city from 2008 to 2017 shows that the number of health technicians per 1,000 population in A city has risen steadily in the past 10 years, from 5.02 in 2008 to 6.56 in 2017, especially from 2011 to 2012 and 2013 to 2014. From this single index, we can see that the amount of health human resources available in A city has been significantly increased since the new medical reform, and the amount of health clothing has been improved. By the end of 2017, compared with the overall situation of S province, the percentage of health technicians in A city was basically the same as that in the whole province. The proportion of other health technicians was slightly higher than that in the whole province, and the proportion of managers and workers was lower than that in the whole province. The percentages of health workers and management workers are lower than those of other cities in the city of A. Compared with other cities in S Province, the percentage of other health and technical personnel in the city of A is the highest in the city, and the percentage in the city is the highest in the city of A.

Table 1. Gender structure of health human resources of A city in 2017

\begin{tabular}{|c|c|c|}
\hline Item & Number & Proportion \\
\hline Total persons & 40178 & $100.0 \%$ \\
\hline Male & 22540 & $56.1 \%$ \\
\hline Female & 17638 & $43.9 \%$ \\
\hline
\end{tabular}

Table 2. Professional rank structure of health human resources of A city in 2017

\begin{tabular}{|c|c|c|}
\hline Item & Number & Proportion \\
\hline Total persons & 40178 & $100.0 \%$ \\
\hline Senior & 3708 & $9.2 \%$ \\
\hline Intermediate & 13098 & $32.6 \%$ \\
\hline Junior & 19442 & $48.4 \%$ \\
\hline Others & 3929 & $9.8 \%$ \\
\hline
\end{tabular}

Table 3. Duty structure of health human resources of A city in 2017

\begin{tabular}{|c|c|c|}
\hline Item & Number & Proportion \\
\hline Total persons & 40178 & $100.0 \%$ \\
\hline
\end{tabular}




\begin{tabular}{|c|c|c|} 
Technician & 33126 & $82.4 \%$ \\
\hline Administrators & 4002 & $10.0 \%$ \\
\hline Others & 3050 & $7.6 \%$ \\
\hline
\end{tabular}

Table 4. Health manpower and population ratio from 1998 to 2017 in City A

\begin{tabular}{|c|c|c|c|}
\hline Year & $\begin{array}{c}\text { Population (thousand } \\
\text { persons) }\end{array}$ & $\begin{array}{c}\text { Health manpower (thousand } \\
\text { persons) }\end{array}$ & Ratio \\
\hline 2008 & 5758.96 & 28.91 & 5.02 \\
\hline 2009 & 5788.54 & 29.29 & 5.06 \\
\hline 2010 & 5760.08 & 30.01 & 5.21 \\
\hline 2011 & 5841.81 & 31.02 & 5.31 \\
\hline 2012 & 5764.81 & 32.11 & 5.57 \\
\hline 2013 & 6001.78 & 33.67 & 5.61 \\
\hline 2014 & 6257.19 & 36.98 & 5.91 \\
\hline 2015 & 6259.32 & 38.62 & 6.17 \\
\hline 2016 & 6340.16 & 40.26 & 6.35 \\
\hline 2017 & 6429.88 & 42.18 & 6.56 \\
\hline
\end{tabular}

Table 5. Duty structure of health human resources of each city in province S in 2017

\begin{tabular}{|c|c|c|c|l|}
\hline Item & Total persons & Technician & Administrators & Others \\
\hline Province S & 440677 & 357261 & 39750 & 43666 \\
\hline City A & 40178 & 33126 & 4002 & 3050 \\
\hline City B & 40005 & 32601 & 3556 & 3848 \\
\hline City C & 38256 & 33284 & 3216 & 1756 \\
\hline City D & 37489 & 30004 & 3103 & 4382 \\
\hline City E & 39696 & 32365 & 4123 & 3208 \\
\hline City F & 38415 & 30156 & 3894 & 4365 \\
\hline City G & 44451 & 33028 & 3976 & 7447 \\
\hline City H & 42231 & 36023 & 2451 & 3757 \\
\hline City I & 39498 & 30458 & 4236 & 4804 \\
\hline City J & 37456 & 30467 & 3167 & 3822 \\
\hline City K & 43002 & 35749 & 4026 & 3227 \\
\hline
\end{tabular}

Table 6. Health manpower and population ratio in each city in Province S in 2017

\begin{tabular}{|c|c|}
\hline Year & Ratio \\
\hline Province S & 6.01 \\
\hline City A & 6.56 \\
\hline City B & 6.07 \\
\hline City C & 5.98 \\
\hline City D & 6.23 \\
\hline City E & 6.54 \\
\hline City F & 6.81 \\
\hline City G & 6.72 \\
\hline City H & 5.86 \\
\hline City I & 5.91 \\
\hline
\end{tabular}




\begin{tabular}{|c|c|} 
City J & 5.93 \\
\hline City K & 6.32 \\
\hline
\end{tabular}

\section{Discrete dynamic forecasting model of health human resources in A city}

\subsection{Forecasting result of manpower and population ratio}

The manpower and population ratio method is one of the four classical methods recommended by WHO for predicting health manpower. The number of health manpower in the target year can be calculated according to the predicted population and the human-to-population ratio. For the target years, the prediction of health man and population ratio can be obtained by trend extrapolation method.

Table 7. Population growth rate of and ratio of health manpower to population in A city

\begin{tabular}{|l|l|l|l|}
\hline Year & $\begin{array}{l}\text { Population (thousand } \\
\text { persons) }\end{array}$ & Growth rate & $\begin{array}{l}\text { Ratio of health manpower } \\
\text { to population }\end{array}$ \\
\hline 2008 & 5759 & - & $0.50 \%$ \\
\hline 2009 & 5789 & $0.51 \%$ & $0.51 \%$ \\
\hline 2010 & 5798 & $0.16 \%$ & $0.52 \%$ \\
\hline 2011 & 5842 & $0.76 \%$ & $0.53 \%$ \\
\hline 2012 & 5903 & $1.05 \%$ & $0.56 \%$ \\
\hline 2013 & 6002 & $1.67 \%$ & $0.56 \%$ \\
\hline 2014 & 6257 & $4.26 \%$ & $0.59 \%$ \\
\hline 2015 & 6259 & $0.03 \%$ & $0.62 \%$ \\
\hline 2016 & 6340 & $1.29 \%$ & $0.64 \%$ \\
\hline 2017 & 6430 & $1.42 \%$ & $0.66 \%$ \\
\hline & Average growth rate $1.24 \%$ & Average ratio $0.568 \%$ \\
\hline
\end{tabular}

Based on the ratio of population size to average growth rate and average manpower population in A city of government health manpower resources. The mean square error is 11.72 .

Table 8. Forecasting result of manpower and population ratio

\begin{tabular}{|c|c|c|c|}
\hline Year & Population (Prediction) & $\begin{array}{l}\text { Health manpower } \\
\text { (Prediction) }\end{array}$ & Residual \\
\hline 2008 & 5759 & 32.7 & 3.8 \\
\hline 2009 & 5830.4 & 33.1 & 3.8 \\
\hline 2010 & 5902.7 & 33.5 & 2.9 \\
\hline 2011 & 5975.9 & 33.9 & 2.3 \\
\hline 2012 & 6050.0 & 34.4 & 1.1 \\
\hline 2013 & 6125.0 & 34.8 & -1.8 \\
\hline 2014 & 6201.0 & 35.2 & -3.0 \\
\hline 2015 & 6277.9 & 35.7 & -4.2 \\
\hline 2016 & 6355.7 & 36.1 & -5.6 \\
\hline 2017 & 6434.5 & 36.5 & \\
\hline 2018 & 6514.3 & 37.0 & \\
\hline 2019 & 6595.1 & 37.5 & \\
\hline 2020 & 6676.9 & 37.9 & 38.4 \\
\hline 2021 & 6759.7 & 38.9 & \\
\hline 2022 & 6843.5 & & \\
\hline
\end{tabular}




\subsection{Forecasting result of linear regression method}

According to the statistical yearbook of A in 2018, we can get the total population, GDP and the number of government health manpower resources in A city in $1998 \sim 2017$. We use multiple linear regression model to solve the problem. For convenience of calculation, the number of health human resources per 100 is $\mathrm{x} 2$, and the population per 10000 is $\mathrm{x} 3$, which are the independent variables of $\mathrm{F}$.

$\mathrm{F}(\mathrm{x} 1, \mathrm{x} 2, \mathrm{x} 3, \mathrm{t})=1.236 \mathrm{x} 1-$ $0.869 \times 2+0.652+15.334 t+1236.846$
The model was evaluated by regression analysis and significance test. The $\mathrm{P}$ value of $\mathrm{F}$ statistic was $3.151 * 10-9$, close to 0 , much less than 0.05 , indicating that the regression effect of the equation was remarkable. The $p$ value of $t$ statistic of the regression coefficient of health human resources $\mathrm{x} 1$ in the previous year was 0.0001 , indicating that the original hypothesis was accepted when the significance level was 0.05 , that is, the forecast of health human resources in the previous year was phase. The regression coefficients of population, GDP and T-series in the same jurisdiction are significant, which are related to the number of health human resources. The mean square error is 2.28.

Table 9. Table of regression parameter

\begin{tabular}{|l|l|l|}
\hline & coefficient & P-value \\
\hline $\mathrm{b}$ & 1238.846 & 0.0024 \\
\hline $\mathrm{x} 1$ & 1.236 & 0.0041 \\
\hline $\mathrm{x} 2$ & -0.869 & 0.0091 \\
\hline $\mathrm{x} 3$ & 0.652 & 0.0128 \\
\hline $\mathrm{t}$ & 15.334 & 0.0162 \\
\hline
\end{tabular}

Table 10. Forecasting result of linear regression method

\begin{tabular}{|l|c|c|c|}
\hline Year & Health manpower (Fact) & Health manpower (Prediction) & Residual \\
\hline 2008 & 28.9 & 28.9 & 0.0 \\
\hline 2009 & 29.3 & 29.6 & 0.3 \\
\hline 2010 & 30.0 & 32.1 & 2.1 \\
\hline 2011 & 31.0 & 33.2 & 2.2 \\
\hline 2012 & 32.1 & 34.6 & 2.5 \\
\hline 2013 & 33.7 & 35.6 & 1.9 \\
\hline 2014 & 37.0 & 37.1 & 0.1 \\
\hline 2015 & 38.6 & 38.9 & 0.3 \\
\hline 2016 & 40.3 & 41.5 & 1.2 \\
\hline 2017 & 42.2 & 43.6 & 1.4 \\
\hline 2018 & & 44.5 & \\
\hline 2019 & & 44.9 & \\
\hline 2020 & & 46.2 & \\
\hline 2021 & & 47.3 & \\
\hline 2022 & & 47.8 & \\
\hline
\end{tabular}

\subsection{Forecasting result of grey model}

Grey model is a forecasting method which establishes equation by series of numbers and transforms irregular original series into regular series of numbers. Based on the comprehensive analysis of practical work experience, characteristics of actual data, Time Series graphics and comparison of prediction errors, the grey series model has a better prediction effect in predicting the development trend of health manpower. However, the limitation of this method is that it does not consider the impact of policy. This paper only studies the development trend of the past decade, and the number of various types of health technicians in A city by 2022 . The mean square error is 1.17 . 
Table 11. Forecasting result of grey model

\begin{tabular}{|l|l|l|c|}
\hline Year & $\begin{array}{l}\text { Health manpower } \\
\text { (Fact) }\end{array}$ & $\begin{array}{l}\text { Health } \\
\text { (Prediction) }\end{array}$ & Residual \\
\hline 2008 & 28.91 & 27.6 & -1.31 \\
\hline 2009 & 29.29 & 30.2 & 0.91 \\
\hline 2010 & 30.21 & 31.6 & 1.39 \\
\hline 2011 & 31.02 & 33.6 & 2.58 \\
\hline 2012 & 32.88 & 35.1 & 2.22 \\
\hline 2013 & 33.67 & 36.8 & 3.13 \\
\hline 2014 & 36.98 & 39.1 & 2.12 \\
\hline 2015 & 38.62 & 36.7 & -1.92 \\
\hline 2016 & 40.26 & 40.9 & 0.64 \\
\hline 2017 & 42.18 & 44.1 & 1.92 \\
\hline 2018 & & 44.5 & \\
\hline 2019 & & 45.6 & \\
\hline 2020 & & 45.9 & \\
\hline 2021 & & 46.2 & \\
\hline 2022 & & 48.5 & \\
\hline
\end{tabular}

forecasting are calculated by mean square error. The

\subsection{Result of combination forecasting} process and result are shown in Table 12.

The weights of manpower and population ratio, linear regression method and grey model in combination

Table 12. Weights of combination forecasting

\begin{tabular}{|c|c|c|c|}
\hline & $\begin{array}{c}\text { Manpower } \\
\text { Population Ratio } \\
\text { Method }\end{array}$ & $\begin{array}{c}\text { Linear } \\
\text { Regression } \\
\text { Method }\end{array}$ & $\begin{array}{c}\text { Grey Prediction } \\
\text { Method }\end{array}$ \\
\hline Mean Square Error & 11.72 & 2.28 & 1.17 \\
\hline Reciprocal of Mean Square Error & 0.085 & 0.439 & 0.855 \\
\hline Weight & 0.005 & 0.496 & 0.499 \\
\hline
\end{tabular}

The weighted combination forecasting model of the $\mathrm{Y}=0.005 \mathrm{y} 1+0.496 \mathrm{y} 2+0.499 \mathrm{y} 3$. According to the total number of health workers in A city is combined forecasting model, the total number of health workers in A city from 2018 to 2022 is forecasted.

Table 13. Combination forecasting result of health human resources in A city

\begin{tabular}{|c|c|c|c|}
\hline Year & $\begin{array}{c}\text { Health manpower } \\
\text { (Fact) }\end{array}$ & Health manpower (Prediction) & Residual \\
\hline 2008 & 28.9 & 28.3 & -0.63 \\
\hline 2009 & 29.3 & 29.9 & 0.63 \\
\hline 2010 & 30.0 & 31.9 & 1.85 \\
\hline 2011 & 31.0 & 33.4 & 2.38 \\
\hline 2012 & 32.1 & 34.8 & 2.74 \\
\hline 2013 & 33.7 & 36.2 & 2.52 \\
\hline 2014 & 37.0 & 38.1 & 1.11 \\
\hline 2015 & 38.6 & 37.8 & -0.83 \\
\hline 2016 & 40.3 & 41.2 & 0.91 \\
\hline 2017 & 42.2 & 43.8 & 1.63 \\
\hline 2018 & & 44.5 & \\
\hline 2019 & & 45.2 & \\
\hline 2020 & & 46.0 & \\
\hline 2021 & & 46.7 & \\
\hline 2022 & & 48.1 & \\
\hline
\end{tabular}




\section{Suggestions}

\subsection{Explore scientific forecasting methods}

Health service management involves many disciplines, such as medicine, sociology, economics, management, etc. It has the characteristics of interdisciplinary and interdisciplinary. With the continuous advancement of the global information age and the continuous updating of computers and software, the interdisciplinary intersection and integration have been further promoted. Various econometric methods and models have been gradually integrated into the field of health, promoting the updating of methodology in the field of health research, and making the prediction methods of health human demand diversified. At present, the traditional forecasting methods of health manpower demand are not yet mature, and there are still many problems, such as blindness in the selection of forecasting models, lack of topological innovation, neglect of error analysis of forecasting results, lack of micro-level forecasting of health manpower demand, and so on. In order to further improve the forecasting method of health manpower demand, we should start from the following three aspects. Firstly, based on the comprehensive, systematic and scientific concept, the demand of health human resources is forecasted by taking into account the relevant factors of social, economic, population, culture, environment, disease and so on. Secondly, the prediction of single variable and single model is transformed into the prediction of multi-variable and combination model, and the prediction accuracy and reliability of the model are tested by statistics. Thirdly, according to the categories of health manpower and health services, the forecast variables are selected separately, and a more targeted health manpower demand prediction model is established. For example, the forecasting methods of nursing personnel demand and paediatricians demand provide reference and basis for the formulation of health manpower planning.

\subsection{Readjust health human resource structure}

There are many problems in the structure of health manpower in A city, such as excessive workload of doctors, insufficient number of doctors, inverted proportion of doctors and nurses, and lack of nursing talents. In order to further optimize the structure of health manpower, it is necessary to strengthen the construction of medical and nursing personnel, rationally supplement the number of medical and nursing personnel according to the forecast of health service demand, stabilize the clinical front-line team and ensure the quality of medical service. In order to improve the inversion of the ratio of medical care and the shortage of nursing staff, it is imperative to change the traditional concept of "attaching importance to medical treatment while neglecting prevention", adjust the structure of medical education, and strengthen the training of nursing and related professional health personnel in medical colleges and universities. On the other hand, medical and health institutions also need to attach importance to the construction of nursing personnel, improve the working conditions of nurses and properly improve them. Nursing staff salary and treatment, improve the stability of nursing personnel, avoid the loss of nursing personnel. We should also strengthen the quality training of existing health personnel, such as introducing competition mechanism and incentive mechanism, fully mobilizing the enthusiasm of workers, establishing a reasonable talent echelon and optimizing the health personnel contingent through re-education of in-service personnel, training of knowledge and technology, standardized training of medical education, etc.

\subsection{Guide health human resource training}

To strengthen the communication between health and family planning administrative departments and education departments, health and family planning administrative departments need to timely feedback the forecast results of health manpower demand to education departments, so that education departments can take the forecast of health manpower demand as the basis. According to the type and quantity of health professionals needed, we should adjust the scale and direction of medical education, avoid blindness of medical enrolment, and train medical students too quickly, so as to cultivate health professionals to meet different needs and promote the balance between supply and demand of health manpower. Strengthen general practitioner post training. At present, it is obviously unrealistic to rely solely on school education to train qualified community health service personnel. Efforts to do a good job in training all kinds of talents should be the focus of future work, and strive to cultivate highlevel general practitioners. Job training is not only conducive to the transformation and expansion of community service for large hospital staff, but also provides new posts and improves the quality of staff. In a word, on-the-job training is conducive to making full use of existing resources to meet the needs of service, especially for the construction of community teaching base and the promotion of teaching staff for the standardized training of general practice.

\section{Conclusions}

The total amount of health human resources in A city is moderate, but there are still imbalances in the distribution of health personnel quality and urban-rural distribution. In the aspect of health personnel training, we should innovate the training mode of health personnel and improve the efficiency of health services. In personnel management, improve the enthusiasm of staff. According to the discrete dynamic prediction model, city A should reasonably control hospital expansion.

\section{References}

1. Vyas L. Customization in Civil Service Training: Implications for Outsourcing Human Resources Management[J]. International Journal of Public Administration, 2017(1):1-14. 
2. Binru Han R N, Xi C R M, Qiuping Li R N. Application of case mix index in the allocation of nursing human resources[J]. Journal of Nursing Management, 2018, 5(03):231-248.

3. Felberbauer T, Gutjahr $\mathrm{W}$ J, Doerner $\mathrm{K}$ F. Stochastic project management: multiple projects with multi-skilled human resources[J]. Journal of Scheduling, 2019, 22(3):271-288.

4. Hackley D M, Mumena C H, Gatarayiha A, et al. A Case Study Optimizing Human Resources in Rwanda's First Dental School: Three Innovative Management Tools. [J]. Journal of Dental Education, 2018, 82(6):602-607.

5. Loveday J, Sachdev S P, Cherian M N, et al. Survey of Emergency and Essential Surgical, Obstetric and Anaesthetic Services Available in Bangladeshi Government Health Facilities[J]. World Journal of Surgery, 2017, 41(7):1743-1751.

6. Fee A, Mcgrath-Champ S. The role of human resources in protecting expatriates: insights from the international aid and development sector[J]. International Journal of Human Resource Management, 2017, 28(14):1-26.

7. Streater A, Stoner C, Curchod L, et al. World Federation of Occupational Therapists human resources project 2012 and 2014: Demographic profile of WFOT member organisations[J]. World Federation of Occupational Therapists Bulletin, 2017, 73(1):9-14.

8. Park S, Oh S, Lee Y. The relationships between person-organization value fit and employee attitudes in a Korean government sector[J]. International Journal of Human Resource Management, 2018(2):1-26.

9. Assefa T, Mariam D H, Mekonnen W, et al. Health system's response for physician workforce shortages and the upcoming crisis in Ethiopia: a grounded theory research $[\mathrm{J}]$. Human Resources for Health, 2017, 15(1):86.

10. George $G$, Rhodes B. Is there a financial incentive to immigrate? Examining of the health worker salary gap between India and popular destination countries[J]. Human Resources for Health, 2017, 15(1):74.
11. Gashi L M, Željko Požega, Crnković B. Employees' individual values as a source of human capital[J]. Ekonomska Istraživanja, 2017, 30(1):1057-1072.

12. Oliveira A P C D, Dussault G, Craveiro I. Challenges and strategies to improve the availability and geographic accessibility of physicians in Portugal[J]. Human Resources for Health, 2017, $15(1): 24$.

13. Momeni K, Martinsuo M M. Allocating human resources to projects and services in dynamic project environments[J]. International Journal of Managing Projects in Business, 2018, 11(2):486-506.

14. Mackenzie A, Murphy G T, Audas R. A dynamic, multi-professional, needs-based simulation model to inform human resources for health planning $[\mathrm{J}]$. Human Resources for Health, 2019, 17(1):42.

15. García-Lillo F, Enrique Claver-Cortés, Mercedes Úbeda-García, et al. Mapping the "intellectual structure" of research on human resources in the "tourism and hospitality management scientific domain" [J]. International Journal of Contemporary Hospitality Management, 2018, 30(3):1741-1768.

16. Obermann K, Chanturidze T, Glazinski B, et al. The shaded side of the UHC cube: a systematic review of human resources for health management and administration in social health protection schemes[J]. Health Economics Review, 2018, 8(1):4.

17. Djedovic A, Karabegovic A, Avdagic Z, et al. Innovative Approach in Modeling Business Processes with a Focus on Improving the Allocation of Human Resources[J]. Mathematical Problems in Engineering, 2018, 2018(12):1-14.

18. Bakshi S G. WhatsApp: Is it a solution to daily human resources management in institutional practice? [J]. Indian Journal of Anaesthesia, 2018, 62(3):236-236.

19. Sohrabi B, Vanani I R, Abedin E. Human Resources Management and Information Systems Trend Analysis Using Text Clustering[J]. International Journal of Human Capital and Information Technology Professionals, 2018, 9(3):1-24.

20. Celkevicius R, Russo R F S M. An integrated model for allocation and leveling of human resources in IT projects[J]. International Journal of Managing Projects in Business, 2018, 11(3):234-256. 